\title{
Vibration-Based Tests and Results for the Evaluation of Infill Masonry Walls Influence on the Dynamic Behaviour of Buildings: A Review
}

\author{
Vanni Nicoletti ${ }^{1}\left[\right.$ Davide Arezzo ${ }^{1} \cdot$ Sandro Carbonari ${ }^{1} \cdot$ Fabrizio Gara $^{1}$
}

Received: 6 September 2021 / Accepted: 6 January 2022 / Published online: 18 January 2022

(c) The Author(s) 2022

\begin{abstract}
Tests on infill masonry walls have been widely performed by many researchers and for a long time with the main purpose of characterising the infill performance under earthquake-type excitations. However, most of these works deal with laboratory tests on purpose-built specimens. More recently, vibration-based tests have been also adopted to investigate the influence of the non-structural elements on the dynamic behaviour of buildings, with the advantage that this kind of tests can be performed both on laboratory specimens and on in-situ buildings. However, differently from classical infill tests (i.e., monotonic or cyclic lateral load tests, out of plane tests, etc.), a limited number of works is available in the literature discussing the outcomes and possible procedures for testing infilled structures with vibration-based methods aimed to investigate the role of the non-structural components. This paper presents a literature review of research works dealing with vibration-based tests performed on RC frame structures with the main target of discussing the influence of non-structural components on the dynamics of buildings. Tests on infilled buildings performed during the construction, in operating conditions and after the damage occurred due to earthquake shakings, are discussed. Furthermore, a comprehensive review about papers discussing vibration-based tests performed on infill masonry walls is presented and in-depth investigated with the aim of finding possible correlations between the dynamic test outcomes and the infill geometric and mechanical properties. From this study it comes out the need of further experimental data on both undamaged and damaged infills in order to get more reliable correlations.
\end{abstract}

\section{The Relevance of Dynamic Tests on Infills and Infilled Buildings}

Infill masonry walls in RC frame structures are one of the most common non-structural elements worldwide adopted to build external and internal partition walls. Their widespread use is due to many advantageous aspects, along with the constructive easiness, the high versatility and excellent durability characteristics; indeed, they can be used to fill any type of frame, with any type of shape and to realize any type of openings. Furthermore, they are suitable to realize thermal and acoustical insulation by simply adopting insulation layer fixed on the wall, hollow blocks with low thermal conductivity and/or flanked multi-layer panels with empty spaces between them. Also, they can be suitably modified during the building life without the need of changing or modifying

Vanni Nicoletti

v.nicoletti@pm.univpm.it

1 Department of Civil and Building Engineering, and Architecture, DICEA, Univeristà Politecnica delle Marche, Via Brecce Bianche, 60131 Ancona, Italy the structural members, so, usually, without the need of a structural safety assessment or a new structural design. In the design of new RC frame buildings and in the assessment of the existing ones, it is common practice (also permitted by Standards) to neglect the presence of this non-structural elements and to consider them only in terms of added masses and loads. This assumption leads to greatly simplify the calculation procedures since only the RC frame is considered in the modelling. The approach is usually deemed to be conservative since infills are commonly assumed to be completely damaged at ultimate limit states, so that their influence in terms of stiffness and strength is negligible, while at serviceability limit states the floor displacements (on which the verifications are based) are overestimated. However, detrimental interactions between structural and non-structural elements may develop under lateral loads (i.e., earthquake actions) that cannot be captured by numerical models in which the infill stiffness and strength contributions are disregarded. Indeed, infill walls may trigger some undesirable effects on the building performance, such as the activation of soft storey mechanisms and the shear failure of short sections of unconfined columns due to particular infill 
layouts. Previous phenomena are usually taken under control in new constructions by assuring almost constant inter-storey drifts and by avoiding detrimental infill layouts (e.g., pilotis, ribbon windows) while for existing buildings a suitable Finite Element (FE) model should be developed to assess the structural safety. The activation of these brittle mechanisms has disastrous consequences on the seismic performance of buildings, reducing the building overall ductility and leading to a possible collapse.

Unfortunately, infill modelling is not a simple task: many researchers study this topic over the time, proposing different strategies to consider the stiffness and strength contribution to the performance of buildings subjected to lateral loads. The first studies proposed simplified methodologies consisting in modelling infills with one or two cross diagonal struts $[1,2]$; these approaches have been also recently re-considered and updated [3-7]. More sophisticated models have been proposed as well, consisting in modelling infills with plane elements [8-10]. The development of suitable modelling strategies can also take advantages of evidence resulting from experiments performed on infills. Many researchers conducted tests on infill masonry walls under lateral (InPlane, IP) and Out Of Plane (OOP) quasi-static cyclic loads [11-14] or on shaking tables [15-17]. Obviously, all these tests were conducted on laboratory specimens and under laboratory-controlled conditions, so that the tested structures not always faithfully represent reality, in terms of applied gravity loads, boundary conditions, presence of possible previous damage to structural or non-structural elements, ageing of materials, type of lateral loads applied, etc.

Therefore, the possibility to perform tests on real infilled structures may conduce to an in-deep knowledge on the behaviour of this construction typology and to an improvement of the modelling strategies. Among others, vibrationbased test methodology has gained an increasing interest in the last decades and nowadays it is one of the most common test typology performed on real structures, since it owns many advantages: it is easy to be performed, it requires a not bulky equipment, it can be used both in small and large structures, and usually it does not require the interruption of the building activities. The scope of this kind of tests is that of identifying the dynamic behaviour of the tested element through the measurement of accelerations (or velocities) due to different kind of excitations. The most common and adopted one is the so-called ambient vibration, which is provided by the environment surrounding the tested structure, and it is mainly due to microtremors, wind, and anthropic activities. The excitation can be also artificially provided: it is the case of Impact Load Tests (ILTs) and Forced Vibrations (FVs) using shakers. Finally, another type of natural excitation is that provided by earthquakes, whose intensity varies based on the earthquake magnitude and epicentral distance, as well as on the hypocentre depth, path effects, local amplifications, etc. Data collected from these types of tests allow the identification of the modal parameters that characterize the dynamic behaviour of buildings adopting well-known and consolidated identification techniques nowadays available [18-29]. These methodologies can be divided into two main typologies: Operational Modal Analysis (OMA) and Experimental Modal Analysis (EMA). The former permits to identify the dynamics of structures using only the output measurements, hence it is suitable when the input is unknown or unmeasurable; the latter is used when both input and output are measured. Vibration-based tests can be performed in real buildings, as well as in laboratory specimens; furthermore, they can be used to study the dynamic behaviour that characterize the whole building, or a part of it, and even to investigate a single component, both structural and non-structural. When adopted in real buildings [30-40], they allow the identification of the dynamic behaviour that characterize the building at the moment in which tests are performed (i.e., considering all structural and nonstructural elements, both in terms of masses and stiffnesses, and real mass distributions on the structure).

The experimentally identified dynamic behaviour can be used for many purposes, among which the calibration of numerical models that can be used to develop analysis and seismic assessment of buildings. The calibration process becomes crucial when the assessment of existing buildings and the design of possible retrofitting works are developed with the target to preserve the building from any damage due to earthquakes (as in the case of strategic constructions such as hospitals, police and fire stations, etc.), both to structural and non-structural components, as well as to plants and equipment, in order to guarantee the building occupancy during the post-earthquake emergency management. The calibration process is commonly based on the comparison between experimental and numerical modal parameters of the building, assuming frequencies and mode shapes as target parameters [41-54]. Modelling strategies and mechanical material properties in the numerical model are updated (often iteratively) as long as comparisons show a good agreement. Among the others, the most common elements that are usually calibrated in numerical models are the infills, and in particular their stiffness, since the mass can be easily and with good accuracy estimated once the construction typology is known.

Vibration-based test methodologies have also found a growing application in the field of damage detection on buildings due to ageing of structures, application of gravity loads over time and, mainly, due to exceptional actions, as for example earthquakes. Many authors performed tests or investigated real buildings [55-70] in order to correlate possible building damage to the variation of modal parameters. Obviously, the greatest difficulty is to distinguish between the damage of structural and non-structural 
elements because the former has a more drastic impact in the building safety and use, although damage of nonstructural components may also make the building uninhabitable. A better knowledge of building dynamics can support this task; for example, if vibration tests are performed on the bare structure, the modal parameters of the bare RC frame can be identified and suitably used as a threshold for future comparisons in order to identify a possible structural damage [41]. Together with damage detection, vibration-based tests are increasingly used to perform the Structural Health Monitoring (SHM) of buildings [71-76]. Damage detection and SHM are strongly correlated each other since the building health depends on the level of damage. A widespread methodology to perform the SHM of edifices is based on the monitoring of the building dynamics, which usually consists in measuring the building response over the time (usually vibrations due to ambient noise), in identifying its dynamics from these measurements, and in tracing the evolution of the modal parameters. Anomalous changes can be promptly detected, and countermeasures can be taken.

In this paper a literature review about researches dealing with vibration-based tests on RC frame buildings with infill masonry walls, as well as on single infills, is presented. The aim of the paper is that of furnishing a comprehensive review about possible uses of these kinds of test performed to investigate the non-structural component contribution on the dynamics of frame buildings. Initially, an extensive literature review has been performed, looking for papers dealing with vibration-based dynamic tests on infilled buildings and on infills. The selected papers are divided on the basis of their contents and three main classes are created, which correspond to the three main sections of this work. The first one (Sect. 2) deals with vibration-based tests performed on buildings with the main aim to estimate the influence of the infills on their global dynamic behaviour. Test typologies and outcomes are discussed, together with infill modelling strategies in global FE models of buildings that have been calibrated on the basis of experimental results. Section 3 presents some applications of vibration-based tests performed with the target to identify the infill damage effects on the dynamics of buildings, mainly investigating buildings that suffered earthquake shakings all around the world. Finally, in Sect. 4 a comprehensive review of papers dealing with vibration-based tests performed on infill masonry walls is presented and in-depth analysed. The majority of articles treated in this last section focuses on the OOP dynamic behaviour of infills since it is the easiest to be identified; experimental outcomes are reported and analysed in order to find possible correlations about the dynamics of infills and their characteristics, both geometrical and mechanical.

\section{Effects of Infill Masonry Walls on the Dynamic Behaviour of Buildings}

The presence of infill masonry walls sensibly affects the dynamic behaviour of buildings since it contributes to the mass and stiffness increase of a building. It is well known that in common low- and medium-rise infilled RC frame buildings the contribution of the stiffness increment is predominant over the mass one; consequently, the lateral stiffness of infilled buildings increases, and the resonance frequencies reach higher values than those relevant to the bare frame. Many authors investigated the contribution of infill masonry walls on the dynamics of RC frame structures through vibration-based methods.

Few studies refer to laboratory specimen investigations, as Komur et al. [77], that discussed the effects of infill walls arranged in different patterns and stories of a 1/3-scaled one-bay three-storey RC plane frame. They consider four infill patterns, which allow the investigation of the frame dynamic behaviour in soft-storey and half-filled storey systems. Performing AVTs and through the comparison between bare and infilled solutions, they conclude that the walls significantly increase the lateral stiffness and damping ratios of the frame.

On the contrary, many works deal with vibration-based investigations of the infill contribution on the dynamics of real buildings. All these works refer to existing buildings on which dynamic tests have been performed to address the contribution of infills starting from the interpretation of test results through numerical models. In fact, the dynamic properties extracted from in-situ tests are adopted to calibrate numerical models of the buildings considering the infills presence. Then, comparisons between bare and infilled numerical models made it possible to understand the effect of infills in the dynamic response of buildings. Bovo et al. [78] performed FV tests with an eccentricmass shaker in an infilled RC frame building and they used results to calibrate the infill mechanical properties in the developed FE model. In this study, thirteen infill modelling strategies available in literature are considered and developed to understand which of them better simulate the non-structural element effects. Also, Dhakal et al. [79] adopted modal parameters obtained from in-situ AVTs to calibrate FE models of two four-storey infilled RC frame building in Nepal, and, in addition to the infills, they also calibrate the soil deformability to account for the soil-structure interaction. De Angelis and Pecce [80, 81] calibrated FE models of buildings tested with AVTs and also considering the internal partitions, that are modelled within the refined numerical models. Asgarian and McClure [82] performed model calibrations of two infilled $\mathrm{RC}$ hospital buildings in Canada based on AVT recordings 
on both buildings, as well as Mora et al. [83], who adopted a genetic algorithm to calibrate the infill mechanical properties of a real building built around 1950s. Pan et al. [84] investigated the dynamic behaviour of an infilled RC narrow-rectangle high-rise building located in Singapore and they found that, together with the infill contributions, also the floor IP deformability must be accounted for the FE model calibration procedure. Yun et al. [85], Zhou et al. [86] and Su et al. [87] performed AVTs respectively on four, ten and three infilled RC high-rise buildings located in China. They use experimental results to calibrate FE models of the tested buildings and to investigate the infill mass and stiffness contributions on the global dynamic response of buildings. After their studies, all of them conclude that a large discrepancy on the modal parameters is observed if infills are neglected, and, most important, Zhou et al. [86] illustrated that for high-rise building the infill mass affects the building dynamic properties more than the stiffness, contrarily to what happens for low- and medium-rise constructions. Aras [88] used laboratory compression and shear strength tests performed on infill specimens extracted from an existing infilled RC frame building to determine the infill mechanical properties to be adopted in a refined FE model of the structure. The dynamic response of this numerical model has been compared with the real one obtained both through AVTs and ILTs, the latter performed applying hammer blows on a balcony parapet. O'Reilly et al. [89] discussed the results achieved from measurements performed in four infilled RC frame school buildings in Italy obtained from AVTs and from earthquake-induced vibrations that occurred after the 2016 Central Italy seismic sequence. They highlighted that the modal properties identified in one building during the triggered vibration recording showed a reduction in frequency values with respect to the AVT outcomes, meaning that the modal properties are also sensitive to the intensity of input shaking. The same conclusion is reported in the work of Butt and Omenzetter [90], in which a review of the seismic response trends of an instrumented $\mathrm{RC}$ building located in New Zealand and evaluated using fifty recorded earthquake time histories collected over a period of more than two years, is presented. Similar conclusions are drawn also by Gara et al. [76] in discussing the natural frequencies variation of an infilled RC frame building subjected to the seismic swarm following 2016 Central Italy earthquake.

Table 1 reports the dynamic test typologies performed on the tested buildings and structures discussed above, together with the modelling strategies adopted for infills within the relevant numerical models. The most adopted dynamic test is the AVT typology, due to its already mentioned advantages. Only in few cases FVs are used, mainly due to the difficulties relevant to the in-situ shaker positioning and also because the larger the structure, the greater the force (and hence the mass) to apply by the shaker. Moreover, if the excitation amplitudes reach high values, the building may suffer possible damage, mainly to the non-structural elements and components. ILTs are used only in one work, since they are not very suitable to test real structures, because they can hardly provide an adequate excitation level to the structures. As concerns the infill modelling strategies, many authors adopted the Equivalent Diagonal Strut (EDS) technique, while others prefer the plane elements, adopting bidimensional shell elements. The first methodology has the great advantage to be fast and quite easy to implement, while the second one permits to more faithfully modelling the real behaviour of infills, even if it requires more attention in the modelling and higher computational efforts.

At last, few authors investigated the effects of non-structural components and equipment on the building dynamic
Table 1 Summary of performed dynamic tests on buildings and infill modelling strategies

\begin{tabular}{lll}
\hline Article & Dynamic tests on buildings & Infill modelling strategy \\
\hline Komur et al. [77] & AVTs & - \\
Bovo et al. [78] & FVs (shaker) & EDS \\
Dhakal et al. [79] & AVTs & Shell \\
De Angelis and Pecce [80] & AVTs & EDS \\
De Angelis and Pecce [81] & AVTs & EDS \\
Asgarian and McClure [82] & AVTs & EDS and Shell \\
Mora et al. [83] & AVTs & EDS and Shell \\
Pan et al. [84] & AVTs & Shell \\
Yun et al. [85] & AVTs & EDS \\
Zhou et al. [86] & AVTs & EDS and Shell \\
Su et al. [87] & AVTs & Shell \\
Aras [88] & AVTs and ILTs (Hammer) & Shell \\
O'Reilly et al. [89] & AVTs and FVs (Earthquakes) & EDS \\
But and Omenzetter [90] & FVs (Earthquakes) & EDS \\
\hline
\end{tabular}


behaviour. It is the case of Alembagheri et al. [91], who dynamically tested a full-scale laboratory 3-D steel module with different gypsum-board walls, or Wang et al. [92], who tested a full-scale steel structure specimen over a shaking table focusing also on the effects of interior partitions and plant piping. Also, Astroza et al. [93] tested a full-scale $\mathrm{RC}$ specimen over a shaking table in different construction stages and, moreover, once non-structural components and equipment have been installed, in order to investigate the dynamic interaction between them and the structural members. More specifically, in this last work, each specimen floor has been equipped with special-purpose components depending on the intended use of the floor (offices, server room, intensive care unit and surgery suite of a hospital). Anyway, the small number of available papers dealing with the non-structural components and equipment influence on building dynamics reveals the need to further investigate this topic, since the damage of these elements (or their malfunctioning) reflects in high repair costs, sometimes higher than those referring to the structural rehabilitation, and often their collapse can cause loss of human life.

\section{Vibration-Based Tests for the Damage Assessment of Infilled Structures}

Vibration-based tests can be also used for the damage assessment and detection of infilled structures. In fact, as introduced, damage to both structural and non-structural components, as well as damage to only non-structural ones, reflects in changes on the dynamic behaviour of infilled structures. These variations are mainly due to stiffness degradation issues since the mass remains almost the same, apart from cases in which collapses or wall overturning occur and the building mass change.

These considerations are supported by experimental evidence achieved from dynamic tests performed on laboratory specimens or on real buildings. Guljas et al. [94] performed AVTs on a full-scale three-storey RC frame specimen with masonry infills after having performed FV tests (through shake table tests) that induced damage both to infills and to columns; they observed a clear decrease in frequency values, which reached values even lower than those relevant to the bare frame, so they can demonstrate the presence of both structural and non-structural damage, but they do not quantify the entity of each one. A similar experimental campaign has been performed by Moaveni et al. [95]: they tested a 2/3-scaled three-storey infilled RC frame built on a shaking table following design prescriptions of past codes, and they achieved very similar outcomes. Yousefianmoghadam et al. [96, 97] tested two real infilled RC frame buildings (with two and ten stories) with FVs (shaker), free vibrations and AVTs considering different damage levels of the infills; in detail, the damage was simulated removing progressively some infills throughout the building. They found a progressively decrease in frequencies after the infill damage, together with a frequency decrease with the increasing input excitation level (in terms of acceleration amplitudes), i.e., the frequencies identified from AVT recordings were higher than those identified from $\mathrm{FV}$ and free vibration measurements. Shah et al. [98] tested a half-scale two-storey two-bay infilled RC frame on a shaking table and they induced damage to the non-structural components. In addition to what observed before, the authors noted a damping increasing in the first phases of the tests, then a decrease that the authors imputed to the loss of IP and OOP infill masonry wall stiffness contribution.

AVTs are also widely adopted to investigate the dynamic behaviour of buildings after being subjected to earthquakes. Many works deal with AVTs performed on several buildings in Nepal damaged after the 2015 Gorkha earthquake and its aftershocks. For example, Akhlaghi et al. [99], Furtado et al. [100], Yu et al. [101], Gautam [102] and Barbosa et al. [103] performed AVTs on medium- and high-rise infilled RC frame buildings that suffered damage to both structural and nonstructural elements. Most of these studies focus on the calibration of the relevant FE models, in which the mechanical properties of the damaged infills are calibrated. Obviously, in some cases, the damage to the structural components has been considered as well. Lan et al. [104] present a paper in which AVTs are performed in seven infilled RC frame buildings damaged by the 2017 Puebla-Morelos earthquake in Mexico, in order to identify their dynamic behaviour after the damage. They conclude that in buildings with flexible lateral system infills largely resist the seismic loads, preventing severe damage to the structural system, even if significant damage was observed in buildings with weak-storey irregularities. Benedettini et al. [105] performed AVTs in buildings that suffered soft-storey collapses under the 2009 L'Aquila earthquake in Italy and they discussed on how dynamic tests could help the assessment phase and could indicate if a building is in a serviceability condition.

The usefulness of these dynamic tests becomes more relevant if data of tests performed on the undamaged structures are available as well; indeed, comparing results before and after the damage can lead to understand how the dynamic properties of a buildings are changed and, consequently, to have an indication about the damage severity. However, distinguishing the structural damage from the non-structural one is very complicated. Tests on the bare structure can help, together with numerical investigations. 


\section{Dynamic Tests on Infill Masonry Walls}

IP and OOP tests performed on infill masonry walls led to obtain useful information about the infill behaviour under earthquake loads, because they usually simulate the load conditions that are responsible of damage and even collapse during an earthquake [99-109]. IP loads produce crack patterns on infills that lead to a drastic reduction of the wall stiffness and strength, whereas OOP loads are responsible of infill collapses mainly due to overturning. Obviously, in real infilled buildings subjected to earthquake actions, IP and OOP loads act together, producing high level of damage to infills; in particular, infill OOP collapses inside or outside buildings are a risk for the safety of people. For these reasons, tests on infill masonry walls have been widely performed by several researchers to investigate the behaviour of these non-structural components and to have an estimation of their mechanical properties, being these elements composed by several construction materials characterised by different shapes (e.g., dimensions and shapes of bricks, stones) and properties (e.g., brick, mortal tensile and compression resistance, thicknesses of mortar layers). Indeed, standardize the mechanical properties that characterize a masonry infill typology (as can be done for other construction materials, such as concrete and steel) is almost impossible since they depend on several aspects, along with the materials (type of bricks, type of mortar, type of plaster, number of wall leaf, etc.) and the adopted construction techniques. However, the majority of works available in the literature deal with tests performed on infills under quasi-static monotonic or cyclic IP or OOP loads [11-14], or with infills tested with acceleration (or displacement) time-histories applied through shaking tables [15-17]. The foregoing tests have been performed only in laboratory specimens, being almost impossible to perform them on real structures.

More recently, some authors started to adopt vibrationbased tests to investigate the dynamic behaviour of infill masonry walls. This type of test can be performed both on laboratory and on in-situ infills with the advantage to study the dynamic behaviour of non-structural elements in the real context (e.g., applied loads, boundary conditions). Obviously, the excitation level (in terms of maximum displacements or acceleration amplitudes) provided to the infills in this test typology is lower than that provided in laboratory tests, mainly due to the test protocols and instrumentation issues, but also because a high input level could produce a damage to the in-situ infills. Consequently, vibration-based tests allow the identification of the infill dynamic behaviour in their elastic phase (if infills are not damaged yet), obtaining the modal parameters that characterize the infill vibration modes. The most common vibration-based tests performed are those relevant to the identification of the infill OOP dynamic behaviour, since they require the recording of the wall vibrations in the orthogonal direction of the wall plane; tests relevant to the IP dynamic identification are more complicated to be performed, because vibrations in the IP direction must be measured and walls are usually surrounded by RC frames or other infills. Performing tests on infills in real buildings can be useful to get information about the dynamic behaviour of tested infills, and moreover to investigate those features that influence the infill dynamics, such as the panel stiffness, mass, and boundary conditions. Furthermore, comparing results of several infills belonging to the same infill construction typology (as for example in terms of construction materials and/or thickness) can be useful to have an indication of the homogeneity of the mechanical properties of these walls in a building. Finally, vibrationbased tests can be also used to estimate the infill stiffness that can be adopted to model the infill walls within FE models of buildings in order to appropriately account for their presence [110] avoiding the need to calibrate the model.

Despite many advantages can be attributed to vibrationbased tests, only few works are available in the literature dealing with the application of this test typology to infill masonry walls. Arslan and Durmus [111] performed AVTs on a full-scale one-bay one-storey laboratory RC frame without and with the infill wall with the aim of investigating on the influence of the non-structural element on the IP modal parameters of the frame. Other authors performed dynamic tests to characterize the OOP dynamics of infills. Nicoletti et al. [41, 110] and De Angelis and Pecce [112] performed ILTs (using an instrumented hammer) on several in-situ and laboratory infill masonry walls, while Varum et al. [113] and Furtado et al. [114, 115] adopted AVTs. A totality of forty-nine infill masonry wall OOP tests has been collected and the main features are reported in Table 2. For each tested wall, the main geometrical characteristics of the infill are reported, i.e., length $(\mathrm{L})$, height $(\mathrm{H})$ and thickness $(\mathrm{t})$, and the presence of visible damage and openings are declared. Then, it is pointed out if the wall is plastered or not and it is noteworthy that, even if the plaster reflects in a thickness increase, this is not reported for the sake of simplicity and to make possible comparisons easier. Also, the floor level in which the tested wall is located over the total number of building floors, is reported. In case of laboratory specimens, only the term "specimen" is written. Finally, the natural frequency values characterizing the OOP dynamic behaviour of the walls, are listed; four vibration modes are considered, named with a couple of number $n, m$ that describes the relevant mode shape. In detail, with reference to a specific mode shape, $n$ represents the number of semi-waves along 
Table 2 Summary of tested infill masonry walls and identified OOP frequency values

\begin{tabular}{|c|c|c|c|c|c|c|c|c|c|c|c|c|}
\hline \multirow{2}{*}{$\begin{array}{l}\text { Wall } \\
\mathrm{n}\end{array}$} & \multirow{2}{*}{$\begin{array}{l}\text { Length } \\
{[\mathrm{m}]}\end{array}$} & \multirow{2}{*}{$\begin{array}{l}\text { Height } \\
{[\mathrm{m}]}\end{array}$} & \multirow{2}{*}{$\begin{array}{l}\text { Thickness } \\
\text { [m] }\end{array}$} & \multirow[t]{2}{*}{ Damage } & \multirow[t]{2}{*}{ Openings } & \multirow[t]{2}{*}{ Plaster } & & \multirow[t]{2}{*}{ Floor location } & \multicolumn{4}{|c|}{ Frequency $[\mathrm{Hz}]$} \\
\hline & & & & & & & & & 1,1 & 2,1 & 3,1 & 2,2 \\
\hline \multicolumn{13}{|c|}{ Nicoletti et al. [41] } \\
\hline 1 & 5.05 & 3.18 & 0.20 & No & No & & No & $1 / 4$ & 39.82 & 52.10 & 73.01 & 121.87 \\
\hline 2 & 4.75 & 2.90 & 0.08 & No & No & & No & $1 / 4$ & 16.01 & 29.38 & 51.61 & 51.99 \\
\hline 3 & 4.75 & 2.90 & 0.12 & No & No & & No & $1 / 4$ & 27.83 & 42.21 & 64.75 & 92.71 \\
\hline 4 & 5.05 & 3.18 & 0.20 & No & No & & Yes & $1 / 4$ & 54.67 & 74.84 & 109.56 & 159.43 \\
\hline 5 & 4.75 & 2.90 & 0.08 & No & No & & Yes & $1 / 4$ & 25.34 & 41.83 & 69.08 & 74.35 \\
\hline 6 & 4.75 & 2.90 & 0.12 & No & No & & Yes & $1 / 4$ & 44.73 & 66.03 & 96.35 & 135.61 \\
\hline \multicolumn{13}{|c|}{ Nicoletti et al. [110] } \\
\hline 7 & 4.00 & 2.75 & 0.06 & No & No & No & & Specimen & 16.80 & 27.47 & 46.55 & 57.54 \\
\hline 8 & 4.00 & 2.75 & 0.06 & No & No & No & & Specimen & 17.90 & 29.53 & 45.35 & 59.20 \\
\hline 9 & 2.00 & 2.84 & 0.30 & No & No & No & & $2 / 3$ & 64.73 & 161.74 & 234.82 & 201.52 \\
\hline 10 & 2.10 & 2.84 & 0.12 & No & No & No & & $2 / 3$ & 41.81 & - & - & 151.56 \\
\hline 11 & 3.45 & 2.84 & 0.08 & No & No & No & & $2 / 3$ & 22.10 & 40.28 & 70.99 & 64.57 \\
\hline 12 & 4.00 & 2.75 & 0.06 & No & No & Yes & & Specimen & 17.30 & 31.60 & 49.40 & 63.88 \\
\hline 13 & 4.00 & 2.75 & 0.06 & No & No & Yes & & Specimen & 18.10 & 32.15 & 50.50 & 64.50 \\
\hline 14 & 2.00 & 2.84 & 0.30 & No & No & Yes & & $2 / 3$ & 93.47 & 225.89 & 323.61 & 262.51 \\
\hline 15 & 2.10 & 2.84 & 0.12 & No & No & Yes & & $2 / 3$ & 51.11 & - & 315.57 & 186.50 \\
\hline 16 & 3.45 & 2.84 & 0.08 & & No & Yes & & $2 / 3$ & 34.10 & 70.57 & 112.13 & 99.32 \\
\hline \multicolumn{13}{|c|}{ De Angelis and Pecce [112] } \\
\hline 17 & 5.10 & 3.48 & 0.12 & No & No & & Yes & $3 / 4$ & 18.43 & 31.14 & 49.65 & 57.04 \\
\hline \multicolumn{13}{|c|}{ Varum et al. [113] } \\
\hline 18 & 3.90 & 2.20 & 0.20 & No & No & Yes & & $3 / 3$ & 31.83 & 45.02 & 79.91 & - \\
\hline 19 & 2.70 & 2.20 & 0.25 & No & No & Yes & & $3 / 3$ & 46.43 & 77.11 & 114.10 & - \\
\hline 20 & 3.90 & 2.20 & 0.20 & No & Yes & - & & $3 / 3$ & 10.07 & 61.39 & 135.30 & - \\
\hline 21 & 1.60 & 2.60 & 0.30 & No & No & Yes & & $6 / 15$ & 53.49 & 131.10 & 150.70 & - \\
\hline 22 & 1.60 & 2.60 & 0.30 & Yes & No & Yes & & $6 / 15$ & 35.74 & 56.32 & 78.02 & - \\
\hline 23 & 3.10 & 2.60 & 0.30 & No & No & Yes & & $1 / 15$ & 44.03 & 75.01 & 114.80 & - \\
\hline 24 & 3.10 & 2.60 & 0.30 & Yes & No & Yes & & $1 / 15$ & 20.41 & 34.35 & 50.30 & - \\
\hline \multicolumn{13}{|c|}{ Furtado et al. [114] } \\
\hline 25 & 3.50 & 1.30 & 0.11 & No & No & No & & $1 / 6$ & 31.70 & - & - & - \\
\hline 26 & 3.50 & 1.30 & 0.11 & No & No & No & & $1 / 6$ & 24.50 & - & - & - \\
\hline 27 & 3.55 & 3.20 & 0.11 & No & No & No & & $1 / 6$ & 16.50 & - & - & - \\
\hline 28 & 3.20 & 0.95 & 0.11 & No & No & No & & $1 / 6$ & 22.40 & - & - & - \\
\hline 29 & 3.55 & 3.20 & 0.11 & No & No & No & & $1 / 6$ & 30.00 & - & - & - \\
\hline 30 & 2.75 & 3.20 & 0.11 & No & No & No & & $1 / 6$ & 22.50 & - & - & - \\
\hline 31 & 2.45 & 3.20 & 0.11 & No & No & No & & $1 / 6$ & 22.70 & - & - & - \\
\hline 32 & 5.00 & 1.75 & 0.15 & No & No & No & & $4 / 6$ & 18.00 & - & - & - \\
\hline 33 & 2.75 & 2.30 & 0.15 & No & No & No & & $4 / 6$ & 34.20 & - & - & - \\
\hline 34 & 3.60 & 1.00 & 0.11 & No & No & No & & $3 / 6$ & 34.10 & - & - & - \\
\hline 35 & 3.20 & 2.80 & 0.22 & No & Yes & No & & $3 / 6$ & 11.50 & - & - & - \\
\hline 36 & 3.40 & 2.80 & 0.22 & No & No & No & & $3 / 6$ & 28.20 & - & - & - \\
\hline 37 & 3.70 & 2.80 & 0.22 & No & No & No & & $3 / 6$ & 27.60 & - & - & - \\
\hline 38 & 2.10 & 3.20 & 0.11 & No & No & No & & $3 / 6$ & 14.70 & - & - & - \\
\hline 39 & 3.90 & 2.70 & 0.11 & No & No & Yes & & $3 / 3$ & 22.40 & - & - & - \\
\hline 40 & 3.80 & 2.70 & 0.11 & No & Yes & Yes & & $3 / 3$ & 18.20 & - & - & - \\
\hline 41 & 3.50 & 2.70 & 0.11 & No & No & Yes & & $3 / 3$ & 27.30 & - & - & - \\
\hline 42 & 3.15 & 2.55 & 0.08 & No & Yes & Yes & & $1 / 5$ & 53.57 & - & - & - \\
\hline 43 & 3.15 & 2.55 & 0.15 & No & Yes & Yes & & $1 / 5$ & 53.48 & - & - & - \\
\hline
\end{tabular}


Table 2 (continued)

\begin{tabular}{|c|c|c|c|c|c|c|c|c|c|c|c|}
\hline \multirow{2}{*}{$\begin{array}{l}\text { Wall } \\
\mathrm{n}\end{array}$} & \multirow{2}{*}{$\begin{array}{l}\text { Length } \\
\text { [m] }\end{array}$} & \multirow{2}{*}{$\begin{array}{l}\text { Height } \\
{[\mathrm{m}]}\end{array}$} & \multirow{2}{*}{$\begin{array}{l}\text { Thickness } \\
{[\mathrm{m}]}\end{array}$} & \multirow[t]{2}{*}{ Damage } & \multirow[t]{2}{*}{ Openings } & \multirow[t]{2}{*}{ Plaster } & \multirow[t]{2}{*}{ Floor location } & \multicolumn{4}{|c|}{ Frequency [Hz] } \\
\hline & & & & & & & & 1,1 & 2,1 & 3,1 & 2,2 \\
\hline 44 & 3.05 & 2.55 & 0.11 & No & Yes & Yes & $3 / 5$ & 64.45 & -- & - & - \\
\hline 45 & 3.05 & 2.55 & 0.15 & No & Yes & Yes & $3 / 5$ & 57.13 & -- & - & - \\
\hline 46 & 3.50 & 2.80 & 0.11 & No & No & Yes & $3 / 5$ & 31.36 & - & -- & - \\
\hline 47 & 4.20 & 2.30 & 0.15 & No & No & No & Specimen & 20.77 & - & - & - \\
\hline \multicolumn{12}{|c|}{ Furtado et al. [115] } \\
\hline 48 & 4.20 & 2.30 & 0.15 & No & No & No & Specimen & 24.31 & - & - & - \\
\hline 49 & 4.20 & 2.30 & 0.11 & No & No & No & Specimen & 31.00 & - & - & - \\
\hline
\end{tabular}

Mode 1,1

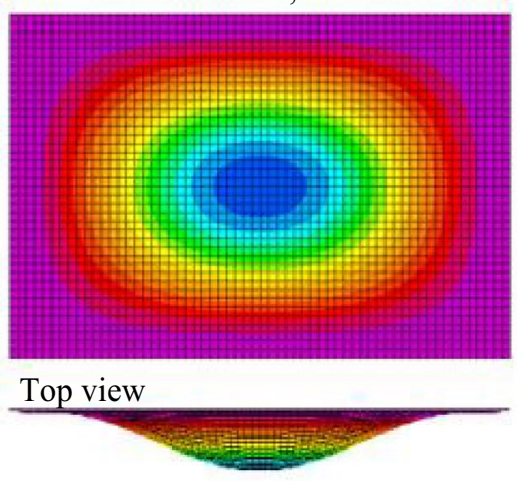

Mode 3,1
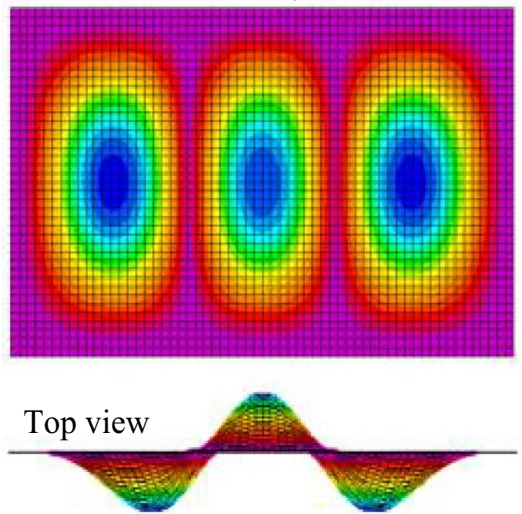
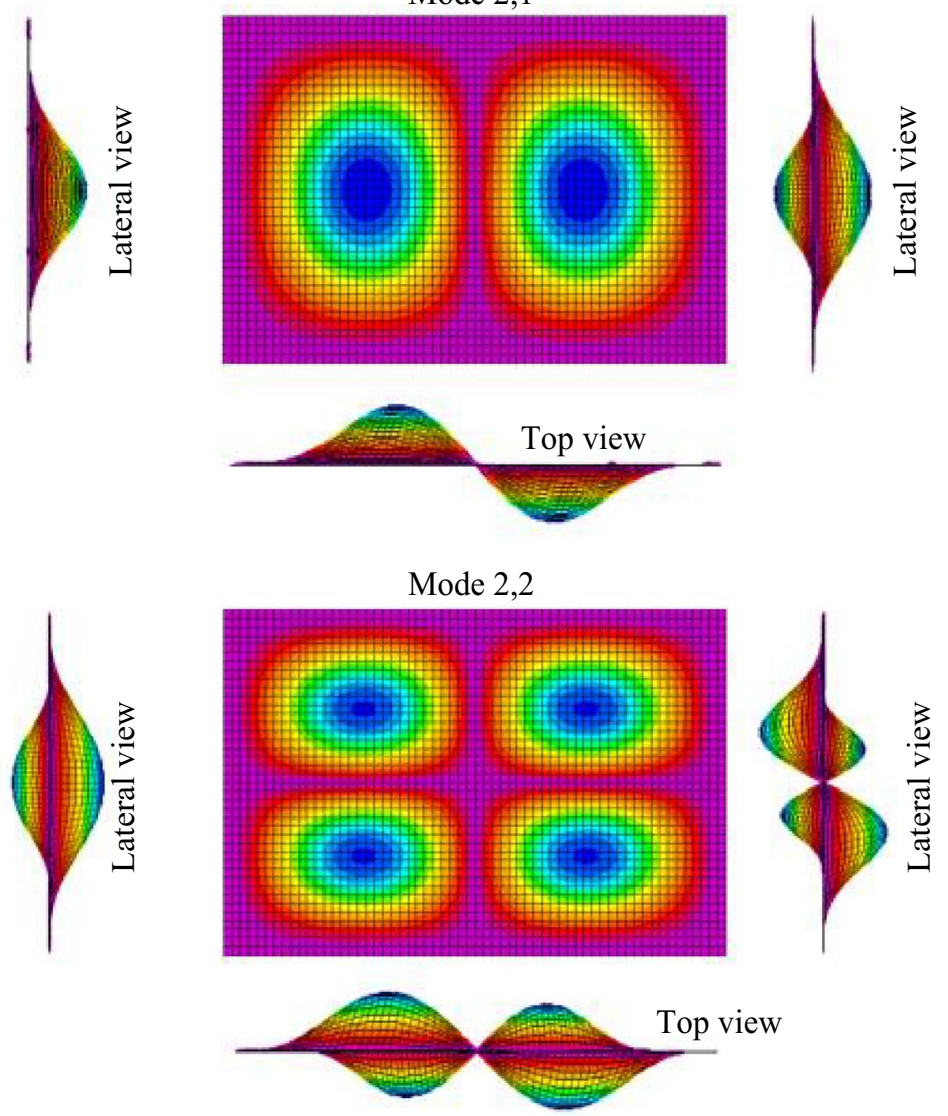

The main characteristics of tested walls are analysed through the support of pie-chart diagrams showed in Fig. 2. As for the presence of visible damage, it is evident that the majority of tested infills did not suffered any damage. Furthermore, the great majority of walls have no openings. About half of the infills is plastered and only in one case it has not been possible to find information on this. Concerning the thicknesses, it is worth noting that all the walls are built adopting nine different thicknesses, ranging from 0.06 to $0.30 \mathrm{~m}$ (namely, from weak to strong infill typology). 


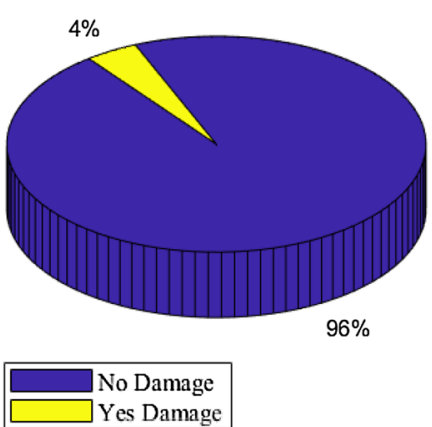

(a)

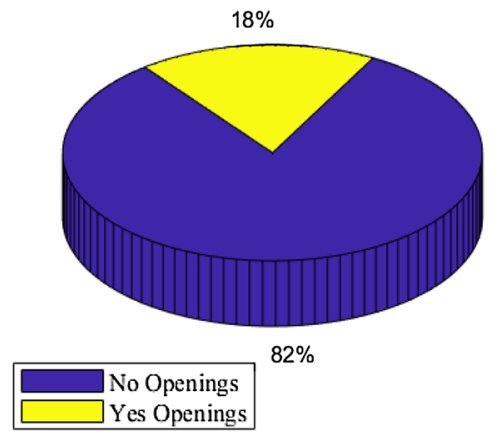

(b)

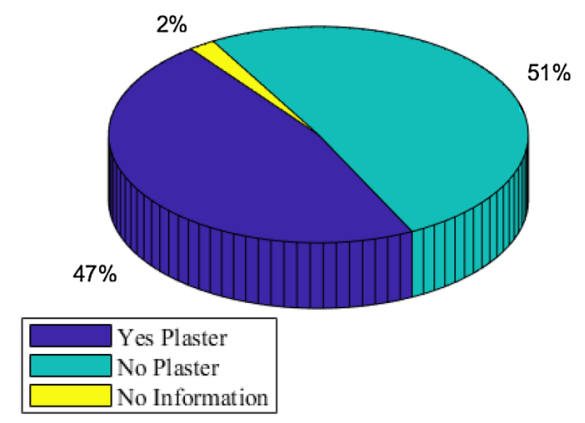

(c)

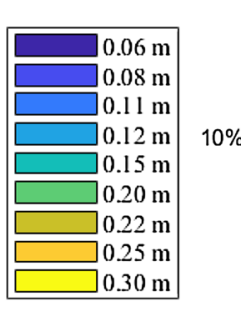

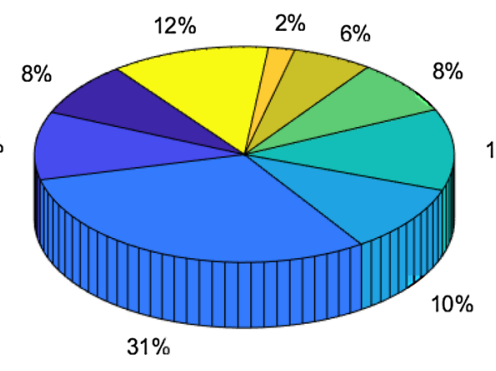

(d)

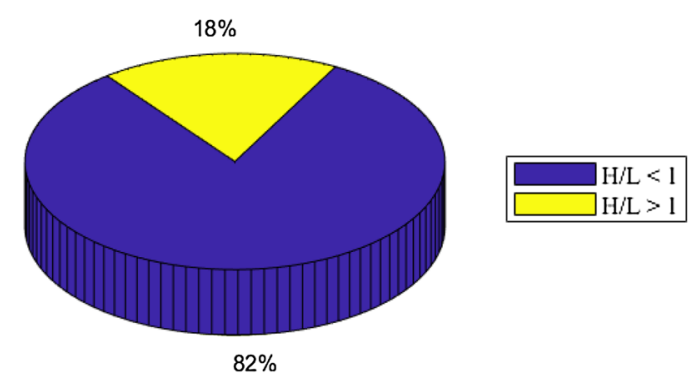

(e)

Fig. 2 Main characteristics of tested walls: a presence of damage, $\mathbf{b}$ presence of openings, $\mathbf{c}$ presence of plaster, $\mathbf{d}$ infill thickness, $\mathbf{e}$ aspect ratio $(\mathrm{H} / \mathrm{L})$

The last pie-chart (Fig. 2e) refers to the infill aspect ratio $\mathrm{H} / \mathrm{L}$, calculated as the ratio between the height and length of the panel. As can be seen, the majority of infills have an $\mathrm{H} / \mathrm{L}$ value lower than one, meaning that the walls are wider than high.

Figure 3 shows different graphs in which the frequency values of Table 2 are plotted against some infill features to find possible correlations between them. In the graphs on the left-hand-side only the fundamental frequency values are plotted, whereas in those on the right-hand-side all frequency values are considered. The markers coloured in blue refer to infills without plaster (i.e., No Plaster, NP), whereas those on red refer to the case with Plaster $(\mathrm{P})$; moreover, an empty marker refers to infills without openings (i.e., No Openings, NO), while the filled one to infill with Openings $(\mathrm{O})$. It is worth noting that the frequency values relevant to damaged infills (two walls from the experimentation of Varum et al. [113]) are neglected to obtain correlations referring only to infills without damage. In Fig. 3a the frequency values are plotted against the panel aspect ratio $(\mathrm{H} / \mathrm{L})$ and an upward frequency trend is observed with the $\mathrm{H} / \mathrm{L}$ ratio increase. In Fig. $3 b$ frequencies are correlated with the panel slenderness, the latter defined as the ratio $\mathrm{H} / \mathrm{t}$, and here it is possible to identify a downward frequency trend. In Fig. 3c frequency values are plotted against the panel diagonal length and, as before, a downward frequency trend is observed, while in Fig. 3d frequencies are plotted against the infill thickness. As expected, in this last case an upward trend is observed, meaning that frequency values increase if the infill thickness increase as well. To better interpret frequency trends, linear data interpolations are superimposed within the graphs and the coefficients of determination $\left(\mathrm{R}^{2}\right)$ are calculated. The latter coefficient indicates how the adopted linear regression model is able to interpret the experimental data, with values ranging between 0 (no correlation) and 1 (perfect correlation). Observing $R^{2}$ values in Fig. 3 it is possible to note that they are all quite low, meaning that data are characterised by a high dispersion with respect to a linear trend; this may be mainly attributable to the low number of available data, in conjunction with the intrinsic heterogeneity of infill panels. Indeed, if only the fundamental frequency is considered, the correlations considering the aspect ratio, the slenderness and the diagonal length are characterised by $\mathrm{R}^{2}$ around $0.14-0.17$, and they further decrease (around 0.03-0.11) if all frequencies are considered. This means that data are widely scattered with respect to the predicted values; however, a higher order expression, which may lead to reduce $\mathrm{R}^{2}$, is meaningless due to the relatively low number of available experimental data. An improvement may be obtained by excluding some outliers and, more importantly, by collecting a great number of infill OOP test results. In this way, OOP dynamic tests 

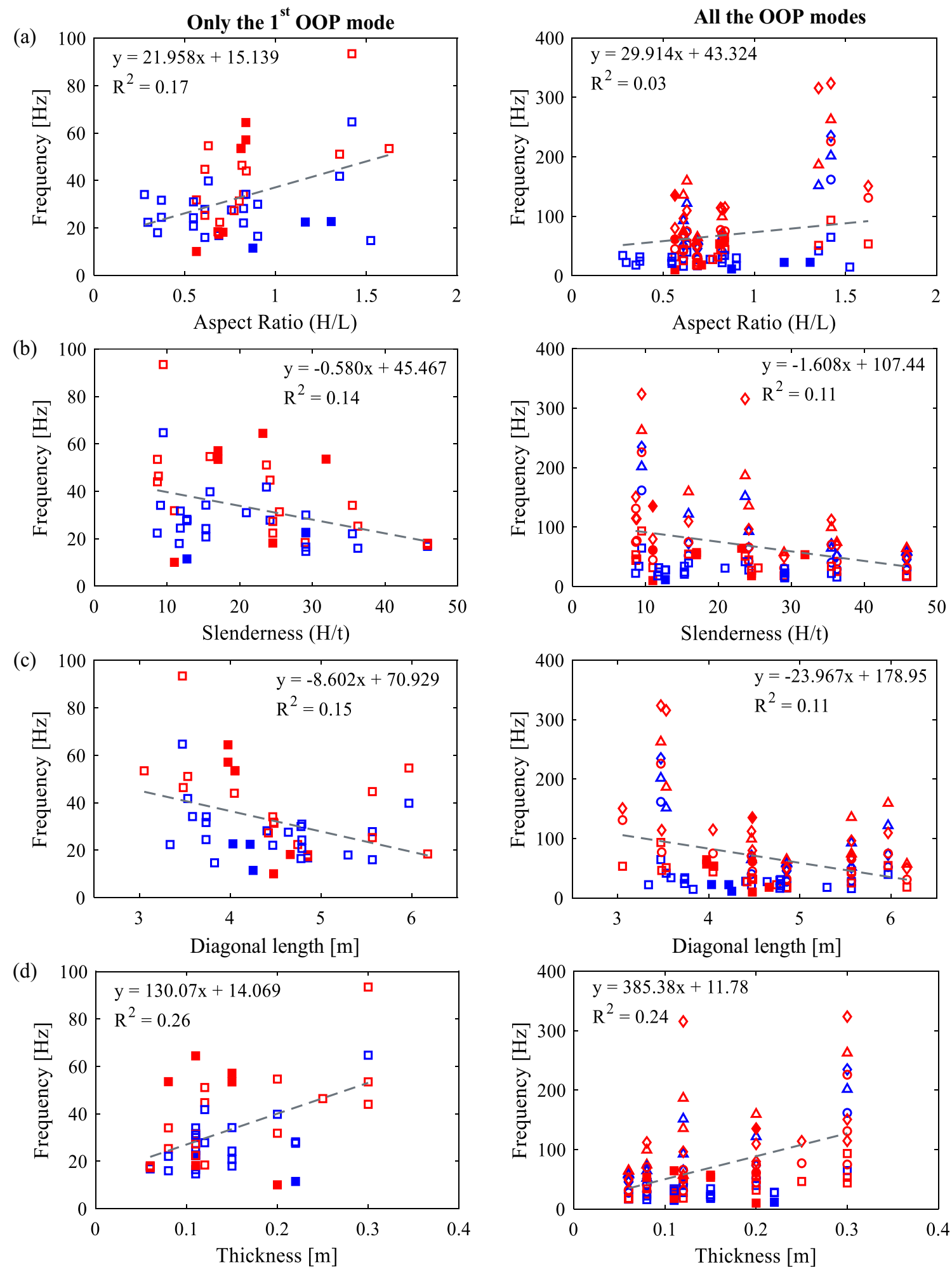
ㅁ $\quad 1^{\text {st }}$ mode: NP - NO
O $2^{\text {nd }}$ mode: NP - NO
$1^{\text {st }}$ mode: P - NO
O $2^{\text {nd }}$ mode: $\mathrm{P}$ - NO
- $1^{\text {st }}$ mode: NP - O
- $2^{\text {nd }}$ mode: NP - O
- $1^{\text {st }}$ mode: P - O
- $2^{\text {nd }}$ mode: $\mathrm{P}$ - O

Fig. 3 Geometric infill parameters correlated with frequencies: a Aspect ratio (H/L), b Slenderness (H/t), c Diagonal length, d Thickness 
on infills are suggested to be further performed and data to be shared among researchers. Anyway, at this state of the art, the proposed linear interpolating functions furnish a rough indication of the frequency trends as a function of the above-mentioned geometric parameters. In addition, it is worth observing that the correlation between frequency and wall thickness is the best one, providing a $\mathrm{R}^{2}=0.26$ in the case in which only the fundamental frequency is considered. Hence, an empirical equation (Eq. 1) can be suggested to interpret the relationship between the fundamental frequency $\mathrm{f}_{1}$ and the panel thickness $\mathrm{t}$ :

$\mathrm{f}_{1}=130.07 \cdot \mathrm{t}+14.069$

Equation 1 can be used to have an estimate of the fundamental OOP frequency value once the wall thickness is known with a mean error of about $30 \%$; if reversed, it can be used to have an estimate of the wall thickness once the fundamental OOP frequency is measured. The latter use could be very useful when dynamic tests on infills are performed in existing buildings, where information about geometric features of the panel are often not available and/or difficult to achieve.

Other works have been found in the literature dealing with dynamic tests on infills, but they are not analysed together with the previous ones since they are not comparable. It is the case of Kernicky et al. [117] that performed ILTs on a partially grouted masonry wall within a full-scale building subjected to internal blast load. Tests on the infill are performed before and after the application of the blast loads; however, the mode shapes identified in both cases are not comparable with those of a typical plate element. Boscato et al. [118] and Oyarzo-Vera and Chouw [119] performed AVTs and ILTs, respectively, on masonry wall laboratory specimens with the aim of identifying their OOP dynamics. Data from these interesting works are not considered in this paper because the specimens are built following the masonry building construction materials and techniques, hence they are not representative of masonry infills in RC frame buildings.

\section{Conclusions}

This paper presented a general review of experimental vibration-based tests carried out to investigate the infill masonry wall contribution on the dynamics of RC frame structures. The main purpose was to discuss the suitability of dynamic tests for applications on whole buildings or parts of them, as well as to discuss about interpretations of their outcomes. A review methodology was adopted, at first performing an extensive literature review and then filtering papers dealing with vibration-based tests performed on infilled $\mathrm{RC}$ frame buildings or on infill masonry walls. Only this infill construction typology is considered (infill with hollow masonry bricks and mortar joints) because it represents the most common and adopted one in RC frame structures worldwide. The selected papers are divided into three main categories: those dealing with the effects of infills in the dynamics of buildings, those relevant to the use of vibration-based tests to identify and investigate the infill damage effects, and those inherent to the dynamic investigation of infills. The works belonging to the first class mainly discuss about the dynamic investigation of real buildings with infills, with the core objective to understand how the mass and stiffness provided by the infills affect the dynamics of structures. Several types of dynamic tests have been adopted, but the most performed one is that based on the ambient vibration measurements, since it owned several advantages, among which the fact that the input is provided by the surrounding environment. It can be pointed out, as a general conclusion, that for low- and medium-rise RC frame building the presence of masonry infills sensibly increase the lateral stiffness of the building, while for high-rise buildings the mass increase revealed to be predominant. Vibration-based tests are also used to investigate the effects of infill damage on the dynamics of buildings. In fact, as well known, damage to both structural and non-structural components reflects in stiffness degradation and, consequently, in changes of the structural modal parameters. Also in this case, mostly ambient vibration tests are performed in buildings with damaged infills after earthquake excitations, and the relevant modal parameters are identified. Obviously, testing structures only after the damage occurrence is not enough to understand if a stiffness degradation is occurred or not and, moreover, to understand the damage severity. Tests performed on the undamaged building can support the damage detection and evaluation, comparing results obtained before and after the damage. If tests are available only after the damage occurrence, the damage severity can be evaluated through numerical investigations adopting a numerical model calibrated based on the experimental outcomes. Finally, in the last part of the paper, tests performed on infill masonry walls with the target to identify their out of plane dynamic behaviour, are presented, and results are analysed. The frequency values identified from different tests performed by several authors are put together and correlated with the main geometric and mechanical infill features. Among the others, an interesting linear equation which correlates the fundamental out of plane wall frequency with the thickness of the panel, is proposed, even if its reliability is not so high, as demonstrated by the relevant low coefficient of determination. However, the empirical correlation can be used to obtain an estimation of the panel thickness simply measuring its out of plane fundamental frequency, or vice versa. This may be useful, 
for example, in case of walls without openings or multi-leaf walls, avoiding the need of invasive tests (e.g., endoscopic tests). To increase the truthfulness of the proposed correlations, more experimental data are necessary. In this way, dynamic tests on infill masonry walls are needed and encouraged to be performed to enlarge the number of the experimental evidence. Moreover, from the literature review proposed in this study, it is evident the lack of tests performed on damaged infills. From the authors point of view, tests on damaged infills should be performed together with dynamic tests on the whole buildings when the health status of damaged buildings is investigated. Additionally, collecting test results on infills with different level of damage can lead to the development of further correlations between the wall modal parameters and its damage status, as well as to correlate the infill damage status to a residual in-plane stiffness suitably to be used in the numerical modelling of buildings.

Author contributions VN: conceptualization, literature search and review, investigation, writing-original draft preparation, writingreview and editing. DA: writing-review and editing. SC: conceptualization, writing-review and editing. FG: conceptualization, writingreview and editing, supervision.

Funding No funding was received to assist with the preparation of this manuscript.

\section{Declarations}

Conflict of interest The authors have no financial or proprietary interests in any material discussed in this article and declare that they have no conflict of interest.

Open Access This article is licensed under a Creative Commons Attribution 4.0 International License, which permits use, sharing, adaptation, distribution and reproduction in any medium or format, as long as you give appropriate credit to the original author(s) and the source, provide a link to the Creative Commons licence, and indicate if changes were made. The images or other third party material in this article are included in the article's Creative Commons licence, unless indicated otherwise in a credit line to the material. If material is not included in the article's Creative Commons licence and your intended use is not permitted by statutory regulation or exceeds the permitted use, you will need to obtain permission directly from the copyright holder. To view a copy of this licence, visit http://creativecommons.org/licenses/by/4.0/.

\section{References}

1. Stafford-Smith B, Carter C (1969) A method for analysis for infilled frames. Proc Inst Civ Eng 7218:31-48

2. Mainstone R.J. (1974) Supplementary note on the stiffness and strength of infilled frames. Current Paper CP 13/74, Building Research Station, Watford, UK

3. Crisafulli FJ, Carr AJ (2007) Proposed macro-model for the analysis of infilled frame structures. Bull N Z Soc Earthq Eng 40(2):69-77
4. Vicente R, Rodrigues H, Arede A, Varum H (2016) Simplified macro-model for infill masonry walls considering the out-ofplane behaviour. Earthq Eng Struct Dyn 45(4):507-524

5. Di Trapani F, Shing PB, Cavaleri L (2018) Macroelement model for in-plane and out-of-plane responses of masonry infills in frame structures. J Struct Eng 144(2):1-13

6. Preti M, Bolis V, Stavridis A (2019) Seismic infill-frame interaction of masonry walls partitioned with horizontal sliding joints: analysis and simplified modeling. J Earthq Eng 23(10):1651-1677

7. Gabbianelli G, Perrone D, Brunesi E, Monteiro R (2020) Seismic acceleration and displacement demand profiles of non-structural elements in hospital buildings. Buildings 10(12):1-19

8. Mehrabi AB, Shing PB (1997) Finite element modelling of masonry-infilled RC frames. J Struct Eng 123(5):604-613

9. Koutromanos I, Stavridis A, Shing PB, Willam K (2011) Numerical modelling of masonry-infilled RC frames subjected to seismic loads. Comp Struct 89(11-12):1026-1037

10. Mazza F (2019) In-plane-out-of-plane non-linear model of masonry infills in the seismic analysis of r.c. framed buildings. Earthquake Eng Struct Dyn 48(4):432-453

11. Petry S, Beyer K (2015) Cyclic test data of six unreinforced masonry walls with different boundary conditions. Earthq Spectra 31(4):2459-2484

12. Frumento S., Magenes G., Morandi P., Calvi G.M. (2009) Interpretation of experimental shear tests on clay brick masonry walls and evaluation of q-factors for seismic design. Research Report EUCENTRE 2009/02, Pavia, IUSS Press

13. Cavaleri L, Fossetti M, Papia M (2005) Infilled frames: developments in the evaluation of cyclic behaviour under lateral loads. Struct Eng Mech 21:469-494

14. Furtado A, Rodrigues H, Arede A, Varum H (2018) Out-of-plane behavior of masonry infilled RC frames based on the experimental tests available: a systematic review. Constr Build Mat 168:831-848

15. Yuen TYP, Zhang HH, Kuang JS, Huang Q (2018) Shake table tests on RC frame infilled by slitted masonry panels. Bull Earthq Eng 16:4027-4052

16. Beyer K, Tondelli M, Petry S, Peloso S (2015) Dynamic testing of a four-storey building with reinforced concrete and unreinforced masonry walls: prediction, test results and data set. Bull Earthq Eng 13:3015-3064

17. Koutromanos I, Kyriakides M, Stavridis A, Billington S, Shing PB (2013) Shake-table tests of a 3-story masonry-infilled RC frame retrofitted with composite materials. J Struct Eng 139(8):1340-1351

18. Brincker R, Ventura CE (2015) Introduction to operational modal analysis, 1st edn. Wiley, Chichester, UK, pp 1-360

19. Rainieri C, Fabbrocino G (2014) Operational modal analysis of civil engineering structures: an introduction and guide applications, 1st edn. Springer, New York, NY, USA, pp 1-314

20. Au SK, Zhang FL, Ni YC (2013) Bayesian operational modal analysis: theory, computation, practice. Comp Struct 126:3-14

21. Aktan A, Brownjohn J (2013) Structural identification: opportunities and challenges. J Struct Eng 139(10):1639-1647

22. Reynders E (2012) System identification methods for (operational) modal analysis: review and comparison. Arch Comput Methods Eng 19:51-124

23. Van Overschee P, De Moor B (2012) Subspace identification for linear systems: Theory-Implementation-Applications. MA, Kluwer Academic Publishers, Norwell

24. Cunha A, Caetano E (2006) Experimental modal analysis of civil engineering structures. Sound Vib 40:12-20

25. Brownjohn JMW (2003) Ambient vibration studies for system identification of tall buildings. Earthq Eng Struct Dyn 32:71-95 
26. Peeters B, De Roeck G (2001) Stochastic system identification for operational modal analysis: a review. J Dyn Syst Meas Contr 123(4):659-667

27. Brincker R, Zhang L, Andersen P (2001) Modal identification of output-only systems using frequency domain decomposition. Smart Mater Struct 10(3):441

28. Ewins DJ (2000) Modal testing: Theory, practice and application, 2nd edn. Wiley, Chichester, UK, pp 1-576

29. Feng MQ, Kim JM, Xue H (1998) Identification of a dynamic system using ambient vibration measurements. J Appl Mech 65:1010-1021

30. Celik OC, Gulkan HP (2020) Processing forced vibration test records of structural systems using the analytic signal. J Vib Control 27(19-20):2253-2267

31. Imposa S, Lombardo G, Panzera F, Grassi S (2018) Ambient vibrations measurements and $1 \mathrm{D}$ site response modelling as a tool for soil and building properties investigation. Geosciences $8(3): 87$

32. Al-Nimry H, Resheidat M, Al-Jamal M (2014) Ambient vibration testing of low and medium rise infilled $\mathrm{RC}$ frame buildings in Jordan. Soil Dyn Earthq Eng 59:21-29

33. Moaveni B, Barbosa AR, Conte JP, Hemez FM (2014) Uncertainty analysis of system identification results obtained for a seven-story building slice tested on the UCSD-NEES shake table. Struct Control Health Monit 21(4):466-483

34. Soyoz S, Taciroglu E, Orakcal K, Nigbor R, Skolnik D, Lus H, Safak E (2013) Ambient and forced vibration testing of a reinforced concrete building before and after its seismic retrofitting. J Struct Eng 139(10):1741-2175

35. Shi W, Shan J, Lu X (2012) Modal identification of Shanghai World Financial Center both from free and ambient vibration response. Eng Struct 36:14-26

36. Ventura CE, Schuster ND (2011) Structural dynamic properties of a reinforced concrete high-rise building during construction. Canad J Civil Eng 23(4):950-972

37. Oliveira CS, Navarro M (2010) Fundamental periods of vibration of RC buildings in Portugal from in-situ experimental and numerical techniques. Bull Earthq Eng 8:609-642

38. Michel C, Gueguen P, Bard PY (2008) Dynamic parameters of structures extracted from ambient vibration measurements: an aid for the seismic vulnerability assessment of existing buildings in moderate seismic hazard regions. Soil Dyn Earthq Eng 28:593-604

39. Hans S, Boutin C, Ibraim E, Roussillon P (2005) In situ experiments and seismic analysis of existing buildings. Part I: experimental investigations. Earthq Eng Struct Dyn 34:1513-1529

40. Chaker AA, Cherifati A (1999) Influence of masonry infill panels on the vibration and stiffness characteristics of $\mathrm{R} / \mathrm{C}$ frame buildings. Earthq Eng Struct Dyn 28:1061-1065

41. Nicoletti V, Arezzo D, Carbonari S, Gara F (2022) Dynamic monitoring of buildings as a diagnostic tool during construction phases. J Build Eng 46:103764

42. Spina D, Acunzo G, Fiorini N, Mori F, Dolce M (2021) A probabilistic simplified Seismic Model from Ambient Vibrations (SMAV) of existing reinforced concrete buildings. Eng Struct 238:112255

43. Sivori D, Lepidi M, Cattari S (2021) Structural identification of the dynamic behavior of floor diaphragms in existing buildings. Smart Struct Syst 27(2):173-191

44. Gara F, Carbonari S, Roia D, Balducci A (2021) Seismic retrofit assessment of a school building through operational modal analysis and f.e. modelling. J Struct Eng 147(1):04020302

45. Foti D, Giannoccaro NI, Vacca V, Lerna M (2020) Structural operativity evaluation of strategic buildings through finite element $(\mathrm{Fe})$ models validated by operational modal analysis (oma). Sensors 20(11):1-23
46. Ierimonti L, Venanzi I, Cavalagli N, Comodini F, Ubertini F (2020) An innovative continuous Bayesian model updating method for base-isolated RC buildings using vibration monitoring data. Mech Syst Signal Process 139:106600

47. Zhang J, Li Q (2019) Identification of modal parameters of a 600-m-high skyscraper from field vibration tests. Earthq Eng Struct D 48(15):1678-1698

48. Zhang FL, Ventura CE, Xiong HB, Lu WS, Pan YX, Cao JX (2018) Evaluation of the dynamic characteristics of a super tall building using data from ambient vibration and shake table tests by a Bayesian approach. Struct Control Health Monit 25(4):e2121

49. Celik OC (2016) Effect of AAC infill walls on structural system dynamics of a concrete building. J Earthq Eng 20(5):738-748

50. Moaveni B, Stavridis A, Lombaert G, Conte JP, Shing PB (2012) Finite-element model updating for assessment of progressive damage in a 3-story infilled RC frame. J Struct Eng 139(10): 1665-1674

51. Michel C, Guéguen P, El Arem S, Mazars J, Kotronis P (2010) Full-scale dynamic response of an RC building under weak seismic motions using earthquake recordings, ambient vibrations and modelling. Earthq Eng Struct Dyn 39:419-441

52. Skolnik D, Lei Y, Yu E, Wallace JW (2006) Identification, model updating, and response prediction of an instrumented 15-story steel-frame building. Earthq Spectra 22(3):781-802

53. Jaishi B, Ren W-X (2005) Structural finite element model updating using ambient vibration test results. J Struct Eng 131(4):617-628

54. Brownjohn JMW (2003) Ambient vibration studies for system identification of tall buildings. Earthq Eng Struct Dyn 32(1):71-95

55. Limongelli M, Giordano P (2020) Vibration-based damage indicators: a comparison based on information entropy. J Civ Struct Health Monit 10:251-266

56. Erazo K, Moaveni B, Nagarajaiah S (2019) Bayesian seismic strong-motion response and damage estimation with application to a full-scale seven story shear wall structure. Eng Struct 186:146-160

57. Shokrani Y, Dertimanis VK, Chatzi E, Savoia MN (2018) On the use of mode shape curvatures for damage localization under varying environmental conditions. Struct Control Health Monit 25(4):e2132

58. Döhler M, Mevel L, Hille F (2014) Subspace-based damage detection under changes in the ambient excitation statistics. Mech Syst Signal Process 45:207-224

59. Moaveni B, He X, Conte JP, Restrepo JI (2010) Damage identification study of a seven-story full-scale building slice tested on the UCSD-NEES shake table. Struct Saf 32(5):347-356

60. Fang S-E, Perera R, De Roeck G (2008) Damage identification of a reinforced concrete frame by finite element model updating using damage parameterization. J Sound Vib 313(3-5):544-559

61. Yan AM, Golinval JC (2006) Null subspace-based damage detection of structures using vibration measurements. Mech Syst Signal Process 20(3):611-626

62. Perera R, Torres R (2006) Structural damage detection via modal data with genetic algorithms. J Struct Eng 132(9):1491-1501

63. Zembaty Z, Kowalski M, Pospisil S (2006) Dynamic identification of a reinforced concrete frame in progressive states of damage. Eng Struct 28:668-681

64. Mucciarelli M, Masi A, Gallipoli MR, Harabaglia P, Vona M, Ponzo F, Dolce M (2002) (2004) Analysis of RC building dynamic response and soil-building resonance based on data recorded during a damaging earthquake (Molise, Italy. Bull Seismol Soc Am 94(5):1943-1953 
65. Hao H, Hia Y (2002) Vibration-based damage detection of structures by genetic algorithm. J Comput Civ Eng 16(3):222-229

66. Ivanovic S, Trifunac M, Novikova E, Gladkov A, Todorovska M (2000) Ambient vibration tests of a seven-story reinforced concrete building in Van Nuys, California, damaged by the 1994 Northridge earthquake. Soil Dyn Earthq Eng 19(6):391-411

67. Doebling SW, Farrar CR, Prime MB (1998) A summary review of vibration-based damage identification methods. Shock Vib 30(2):91-105

68. Salawu OS (1997) Detection of structural damage through changes in frequency: a review. Eng Struct 19(9):718-723

69. Doebling S.W.S., Farrar C.R.C., Prime M.B.M., Shevits D.W.D. (1996) Damage identification and health monitoring of structural and mechanical systems from changes in their vibration characteristics: a literature review. Los Alamos Natl Lab

70. Pandey AK, Biswas M, Samman MM (1991) Damage detection from changes in curvature mode shapes. J Sound Vib 145:321-332

71. Limongelli MP, Celebi M (2019) Seismic structural health monitoring. Springer International Publishing, Cham

72. Das S, Saha P, Patro SK (2016) Vibration-based damage detection techniques used for health monitoring of structures: a review. J Civ Struct Health Monit 6:477-507

73. Boutin C., Hans S. (2009) How far ambient noise measurement may help to assess building vulnerability? In: Increasing seismic safety by combining engineering technologies and seismological data, NATO Science for Peace and Security Series C: Environmental Security, Springer, Dordrecht

74. Sohn H., Farrar C.R., Hemez F.M., Shink D.D., Stinemates D.W., Nadler D.W. (2004) A review of structural health monitoring literature from 1996-2001. Los Alamos National Laboratory report LA-13976-MS

75. Capecchi D, Vestroni F (2000) Monitoring of structural systems by using frequency data. Earthq Eng Struct Dyn 28:447-461

76. Gara F, Arezzo D, Nicoletti V, Carbonari S (2021) Monitoring the modal properties of an RC school building during the 2016 Central Italy seismic swarm. J Struct Eng 147(7):05021002

77. Komur MA, Kara ME, Deneme IO (2020) Infill wall effects on the dynamic characteristics of RC frame systems via operational modal analysis. Struct Eng Mech 74(1):121-128

78. Bovo M, Tondi M, Savoia M (2020) Infill modelling influence on dynamic identification and model updating of reinforced concrete framed buildings. Adv Civ Eng. https://doi.org/10.1155/2020/ 9384080

79. Dhakal R, Rupakhety R, Gautam D (2020) System identification and seismic performance assessment of representative RC buildings in Kathmandu Valley. Front Built Environ 6:601116

80. De Angelis A, Pecce MR (2019) The structural identification of the infill walls contribution in the dynamic response of framed buildings. Struct Control Health Monit 26(9):e2405. https://doi. org/10.3389/fbuil.2020.590114

81. De Angelis A, Pecce MR (2020) The role of infill walls in the dynamic behaviour and seismic upgrade of a reinforced concrete framed building. Front Built Environ 6:590114

82. Asgarian A, McClure G (2014) Impact of seismic rehabilitation and presence of unreinforced masonry (URM) infill walls on the dynamic characteristics of a hospital building in Montreal. Can J Civ Eng 41:748-760

83. Mora ED, Aguirre JJ, Bone JL (2020) Modelling and calibration of infill frame-buildings, using ambient vibration tests and genetic algorithms. Int J Struct Eng 10(4):330-352

84. Pan TC, You X, Brownjohn MW (2006) Effects of infill walls and floor diaphragms on the dynamic characteristics of a narrowrectangle building. Earthq Eng Struct Dyn 35:637-651
85. Yun Z, Yilin P, Yi Z, Hwang HJ, Weijian Y (2020) Field measurements for calibration of simplified models of the stiffening effect of infill masonry walls in high-rise RC framed and shearwall buildings. Earthq Eng Eng Vib 19:87-104

86. Zhou Y, Zhou Y, Yi W, Chen T, Tan D, Mi S (2017) Operational modal analysis and rational finite-element model selection for ten high-rise buildings based on on-site ambient vibration measurements. J Perform Constr Facil 31(5):04017043

87. Su RKL, Chandler AM, Shaikh MN, Lam NTK (2005) Influence of non-structural components on latera stiffness of tall buildings. Struct Design Tall Spec Build 14:143-164

88. Aras F (2018) Laboratory tests and vibration surveys for the mechanical properties of infill walls. J Perform Constr Facil 32(1):04017117

89. O'Reilly GJ, Perrone D, Fox M, Monteiro R, Filiatrault A, Lanese I, Pavese A (2019) System identification and seismic assessment modelling implications for Italian school buildings. J Perform Constr Facil 33(1):04018089

90. Butt F, Omenzetter P (2014) Seismic response trends evaluation and finite element model calibration of an instrumented $\mathrm{RC}$ building considering soil-structure interaction and nonstructural components. Eng Struct 65:111-123

91. Alembagheri M, Sharafi P, Rashidi M, Bigdeli A, Farajian M (2021) Natural dynamic characteristics of volumetric steel modules with gypsum sheathed LSF walls: experimental study. Structures 33:272-282

92. Wang X, Hutchinson TC (2020) Evolution of modal characteristics of a mid-rise cold-formed steel building during construction and earthquake testing. Earthq Eng Struct Dyn 49(14):1539-1558

93. Astroza R, Ebrahimian H, Conte JP, Restrepo JI, Hutchinson TC (2016) Influence of the construction process and nonstructural components on the modal properties of a five-story building. Earthq Eng Struct Dyn 45(7):1063-1084

94. Guljas I, Penava D, Laughery L, Pujol S (2020) Dynamic tests of a large-scale three-story RC structure with masonry infill walls. J Earthq Eng 24(11):1675-1703

95. Moaveni B, Stavridis A, Lombaert G, Conte JP, Shing PB (2013) Finite-element model updating for assessment of progressive damage in a 3-story infilled RC frame. J Struct Eng 139(10):1665-1674

96. Yousefianmoghadam S, Song M, Mohammadi ME, Packard B, Stavridis A, Moaveni B, Wood RL (2020) Nonlinear dynamic tests of a reinforced concrete frame building at different damage levels. Earthq Eng Struct Dyn 49(9):924-945

97. Yousefianmoghadam S, Behmanesh I, Stavridis A, Moaveni B, Nozari A, Sacco A (2018) System identification and modelling of a dynamically tested and gradually damaged 10-story reinforced concrete building. Earthq Eng Struct Dyn 47(1):25-47

98. Shah SAA, Khan JS, Ali SM, Shahzada K, Ahmad W, Shah J (2019) Shake table response of unreinforced masonry and reinforced concrete elements of special moment resisting frame. Adv Civ Eng 2019:7670813

99. Akhlaghi MM, Bose S, Mohammadi ME, Moaveni B, Stavridis A, Wood RL (2021) Post-earthquake damage identification of an RC school building in Nepal using ambient vibration and point cloud data. Eng Struct 227:111413

100. Furtado A, Vila-Pouca N, Varum H, Arede A (2019) Study of the seismic response on the infill masonry walls of a 15-storey reinforced concrete structure in Nepal. Buildings 9(2):39

101. Yu H, Mohammed MA, Mohammadi ME, Moaveni B, Barbosa AR, Stavridis A, Wood RL (2017) Structural identification of an 18 -story RC building in Nepal using post-earthquake ambient vibration and lidar data. Front Built Environ 3:11 
102. Gautam D (2018) Ambient vibration measurements in representative buildings in Kathmandu Valley following the Gorkha earthquake. J Perform Constr Facil 32(3):04018028

103. Barbosa AR, Fahnestock LA, Fick DR, Gautam D, Soti R, Wood R, Moaveni B, Stavridis A, Olsen MJ, Rodrigues H (2017) Performance of medium-to-high rise reinforced concrete frame buildings with masonry infill in the 2015 Gorkha, Nepal, earthquake. Earthq Spectra 33(S1):197-218

104. Lan YJ, Stavridis A, Kim I, Diaz-Fanas G, Hintz J, HernandezBassal L, Anzola E, Berkowitz R, Hussian S, Jalalian A, Garini E, Ktenidou OJ, Yousefianmoghadam S, Carrion H, VallesMattox R, Dominguez MV, Contreras AG, Camacho SRA, Hernandez RFB, Medina VAR, Martinez FV, Vaxevanis T, Hortacsu A, Nikolau S, Gilsanz R (2020) ATC Mw7.1 PueblaMorelos earthquake reconnaissance observations: structural observations and instrumentations. Earthq Spectra 36:31-48

105. Benedettini F, De Sortis A, Milana G (2017) In field data to correctly characterize the seismic response of buildings and bridges. Bull Earthq Eng 15:643-666

106. Vidal F, Navarro M, Aranda C, Enomoto T (2014) Changes in dynamic characteristics of Lorca RC buildings from preand post-earthquake ambient vibration data. Bull Earthq Eng 12:2095-2110

107. Singh JP, Agarwal P, Kumar A, Thakkar SK (2014) Identification of modal parameters of a multistoried RC building using ambient vibration and strong vibration records of Bhuj earthquake, 2001. J Earthq Eng 18:444-457

108. Sanada Y, Konishi D, Maidiawati S (2011) Effects of nonstructural brick infills on an Indonesian earthquake-damaged building. Procedia Eng 14:2077-2085

109. Ivanovic SS, Trifunac MD, Novikova EI, Gladkov AA, Todorovska MI (2000) Ambient vibration tests of a seven storey reinforced concrete building in Van Nuys, California, damaged by the 1994 Northridge earthquake. Soil Dyn Earthq Eng 19(6):391-411

110. Nicoletti V, Arezzo D, Carbonari S, Gara F (2020) Expeditious methodology for the estimation of infill masonry wall stiffness through in-situ dynamic tests. Constr Build Mat 262:120807
111. Arslan ME, Durmus A (2013) Modal testing and finite element model calibration of in-filled reinforced concrete frames. J Vib Control 20(13):1946-1959

112. De Angelis A, Pecce MR (2018) Out-of-plane structural identification of a masonry infill wall inside beam-column RC frames. Eng Struct 173:546-558

113. Varum H, Furtado A, Rodrigues H, Dias-Oliveira J, Vila-Pouca N, Arede A (2017) Seismic performance of the infill masonry walls and ambient vibration tests after the Ghorka 2015 Nepal earthquake. Bull Earthq Eng 15(3):1185-1212

114. Furtado A, Rodrigues H, Arede A, Varum H (2017) Modal identification of infill masonry walls with different characteristics. Eng Struct 145:118-134

115. Furtado A, Rodrigues H, Arede A, Varum H (2016) Experimental evaluation of out-of-plane capacity of masonry infill walls. Eng Struct 111:48-63

116. Mitchell AK, Hazell CR (1986) A simple frequency formula for clamped rectangular plates. J Sound Vib 118(2):271-281

117. Kernicky TP, Whelan MJ, Weggel DC, Rice CD (2015) Structural identification and damage characterization of a masonry infill wall in a full-scale building subjected to internal blast load. J Struct Eng 141(1):D4014013

118. Boscato G, Reccia E, Cecchi A (2018) Non-destructive experimentation: Dynamic identification of multi-leaf masonry walls damaged and consolidated. Compos B Eng 133:145-165

119. Oyarzo-Vera C, Chouw N (2017) Damage identification of unreinforced masonry panels using vibration-based techniques. Shock Vib 2017:9161025

Publisher's Note Springer Nature remains neutral with regard to jurisdictional claims in published maps and institutional affiliations. 